\title{
Progressive postnatal pansynostosis: an insidious and pernicious form of craniosynostosis
}

\author{
Benjamin C. Wood, MD, ${ }^{1}$ Albert K. Oh, MD, ${ }^{1}$ Robert F. Keating, MD, ${ }^{2}$ Michael J. Boyajian, MD, ${ }^{1}$ \\ John S. Myseros, MD, ${ }^{2}$ Suresh N. Magge, MD, ${ }^{2}$ and Gary F. Rogers, MD, JD, MBA, MPH ${ }^{1}$ \\ Departments of ${ }^{1}$ Plastic Surgery and ${ }^{2}$ Neurosurgery, Children's National Health System, Washington, DC
}

OBJECT Progressive postnatal pansynostosis (PPP) is a rare form of craniosynostosis that is characterized by a normal head shape, insidious decrease in percentile head circumference, and high rates of elevated intracranial pressure (ICP). This investigation describes the clinical, radiographic, and genetic features of this entity.

METHODS The authors' craniofacial database for the period 1997-2013 was retrospectively culled to identify patients who had a normal or near-normal head shape and CT-confirmed multiple-suture synostosis. Patients with kleeblattschädel or previous craniofacial surgery were excluded. All demographic information was collected and analyzed.

RESULTS Seventeen patients fit the inclusion criteria. Nine patients had a syndromic diagnosis: Crouzon syndrome $(n=4)$, Pfeiffer syndrome $(n=2)$, Saethre-Chotzen syndrome $(n=1)$, Apert syndrome $(n=1)$, and achondroplasia $(n$ =1). With the exception of 3 patients with mild turricephaly, all patients had a relatively normal head shape. Patients were diagnosed at an average age of 62.9 months. Nearly all patients had some combination of clinical, radiographic, or ophthalmological evidence of increased ICP.

CONCLUSIONS PPP is insidious; diagnosis is typically delayed because the clinical signs are subtle and appear gradually. All normocephalic infants or children with a known or suspected craniosynostotic disorder should be carefully monitored; any decrease in percentile head circumference or signs/symptoms of increased ICP should prompt CT evaluation. http://thejns.org/doi/abs/10.3171/2015.1.PEDS14464

KEY WORDS pansynostosis; progressive; intracranial pressure; craniosynostosis; craniofacial

$\mathrm{I}$ $\mathrm{N}$ 1851, Virchow penned his now classic treatise on craniosynostosis in which he proposed that cranial growth would be arrested perpendicular to a fused suture, but would be increased in adjacent patent sutures. ${ }^{16}$ This theory, known as Virchow's law, demonstrated that premature fusion of any cranial suture would result in a unique and predictable change in cranial shape, thereby allowing craniofacial surgeons to clinically diagnose craniosynostosis by pattern recognition. While the basic tenets of Virchow's law hold true for most forms of craniosynostosis, the theory was derived from examining the cranial shapes of patients in whom the synostosis occurred in the prenatal period. The effect of more latent sutural fusion in the postnatal period is less well understood.
Progressive postnatal pansynostosis (PPP) is a rare and clinically deceptive form of craniosynostosis that occurs in early infancy. Unlike more common forms of craniosynostosis, this entity typically manifests as a normally proportioned, albeit smaller than average, head shape. .,7,10,11 $^{2}$ The muted effect on calvarial form is attributable to the latent timing of sutural closure, usually occurring in the first 2 years of life. The majority of patients have an associated syndrome-Crouzon syndrome being most com$\operatorname{mon}^{2,11}$ - but the characteristic craniofacial features can be subtle and easily overlooked. Moreover, the absence of significant cranial dysmorphology or phenotypic changes in patients with PPP often results in diagnostic delay and a higher incidence of elevated intracranial pressure (ICP)

ABBREVIATIONS CVR = calvarial vault remodeling; $F O A=$ frontoorbital advancement; $I C P=$ intracranial pressure; $P P P=$ progressive postnatal pansynostosis; $V P=$ ven triculoperitoneal.

SUBMITTED August 29, 2014. ACCEPTED January 9, 2015.

INCLUDE WHEN CITING Published online June 5, 2015; DOI: 10.3171/2015.1.PEDS14464.

DISCLOSURE The authors report no conflict of interest concerning the materials or methods used in this study or the findings specified in this paper. 
than is seen in many other forms of craniosynostosis. ${ }^{11}$ This investigation details the clinical, radiographic, and genetic aspects of PPP from a single institution. We highlight the important diagnostic features of this rare entity and our operative strategy.

\section{Methods}

After obtaining approval from our institutional review board, we reviewed the craniofacial database at our institution from 1997 to 2013 to identify patients diagnosed with multiple-suture fusion and normal or near-normal head shape. Patients with kleeblattschädel or those who had undergone prior craniofacial procedures were excluded.

The following data were collected for each patient: date of birth, sex, age at diagnosis of pansynostosis, syndromic association, head shape, serial measurements of head circumference, signs and symptoms leading to diagnosis (including developmental delay), and pertinent radiological studies including CT and MRI. In addition, CT scans obtained at the time of diagnosis were reviewed by senior plastic surgeons and neurosurgeons to assess for missed or incomplete diagnoses regarding fused sutures in the official radiology report.

\section{Results}

A total of 17 patients were identified: 13 males and 4 females (Table 1). The mean age at definitive diagnosis by CT scan was $62.9 \pm 41.2$ months (range 9-151 months). Molecular testing documented mutations consistent with known syndromes in 9 (52.9\%) of 17 patients: Crouzon $(\mathrm{n}=4)$; Pfeiffer $(\mathrm{n}=2)$; Apert $(\mathrm{n}=1)$; Saethre-Chotzen $(\mathrm{n}=1)$; and achondroplasia $(\mathrm{n}=1)$. Molecular testing in 8 patients was unremarkable.

Overall head shape was normal in 14 (82.4\%) of 17 patients (Figs. 1-3); 2 of these patients (with unidentified or presumed nonsyndromic diagnosis) had either an isolated sagittal ridge or minor scaphocephaly (Fig. 4). The other 3 patients (of whom 2 had Crouzon syndrome or SaethreChotzen syndrome) exhibited an apical elevation near the anterior fontanel at the time of diagnosis (Fig. 5).

Pediatrician records were assessed for early cranial growth. Serial measurement of head circumference ob-
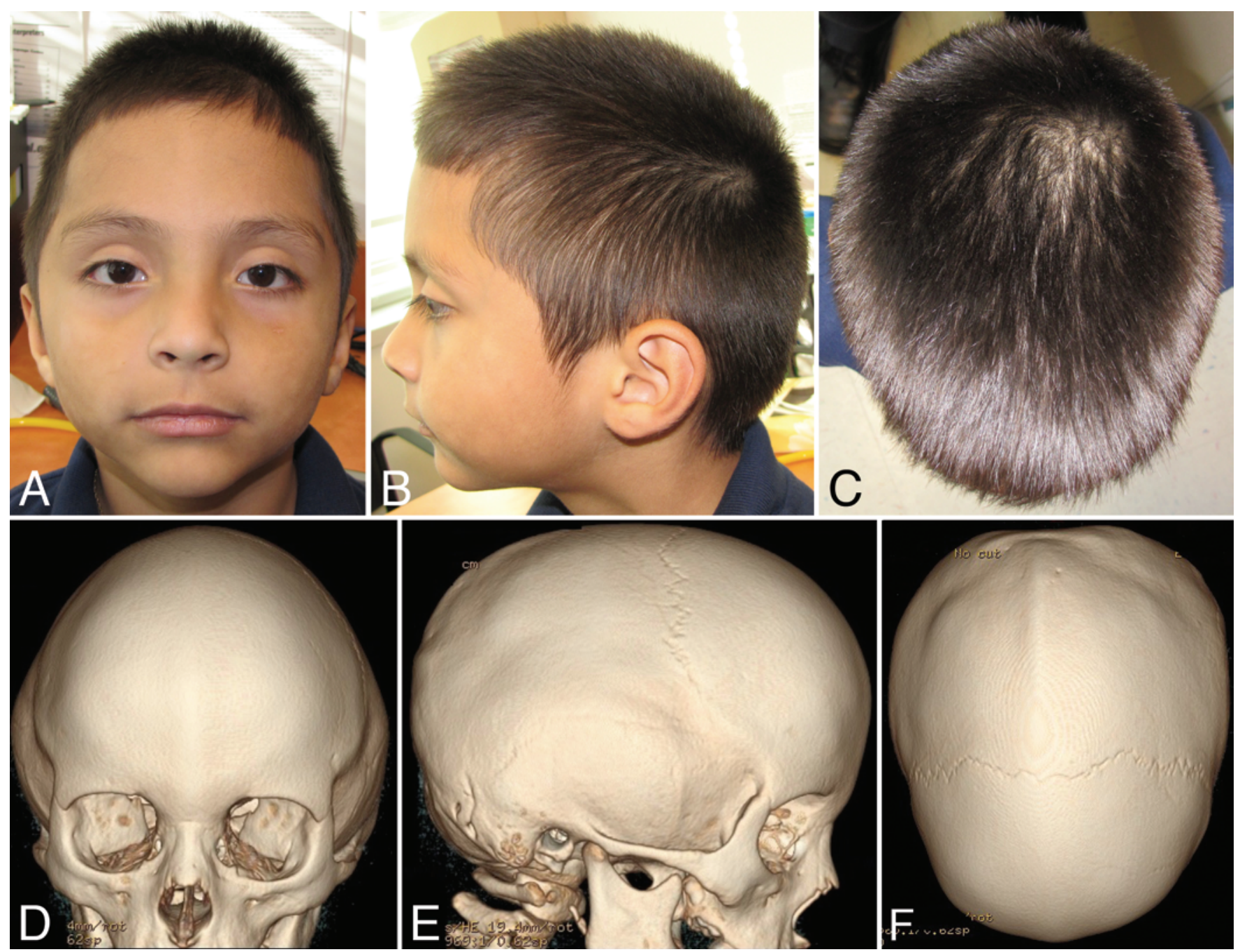

FIG. 1. Patient 1 and CT images (no known syndromic diagnosis). Figure is available in color online only. 


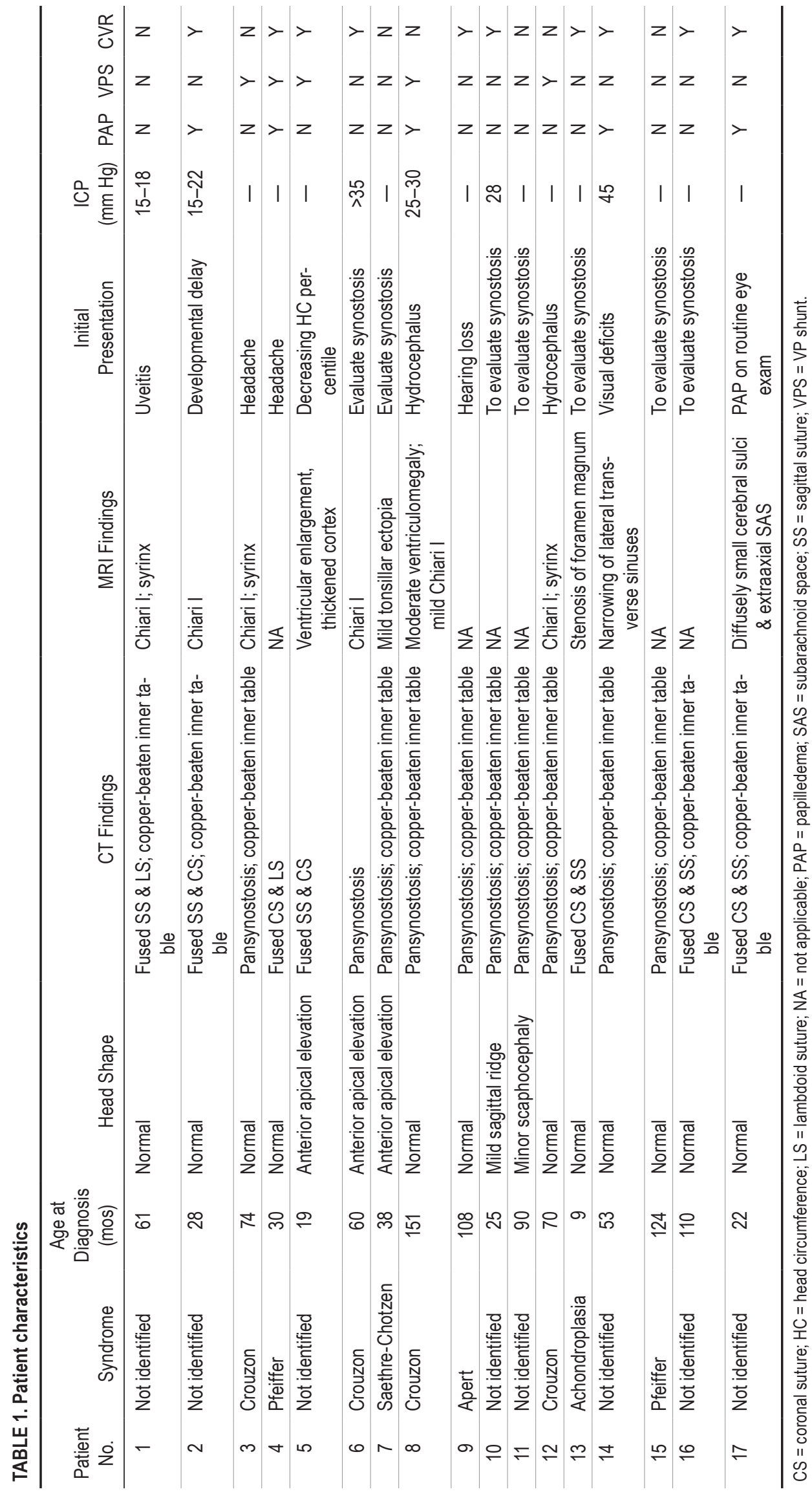



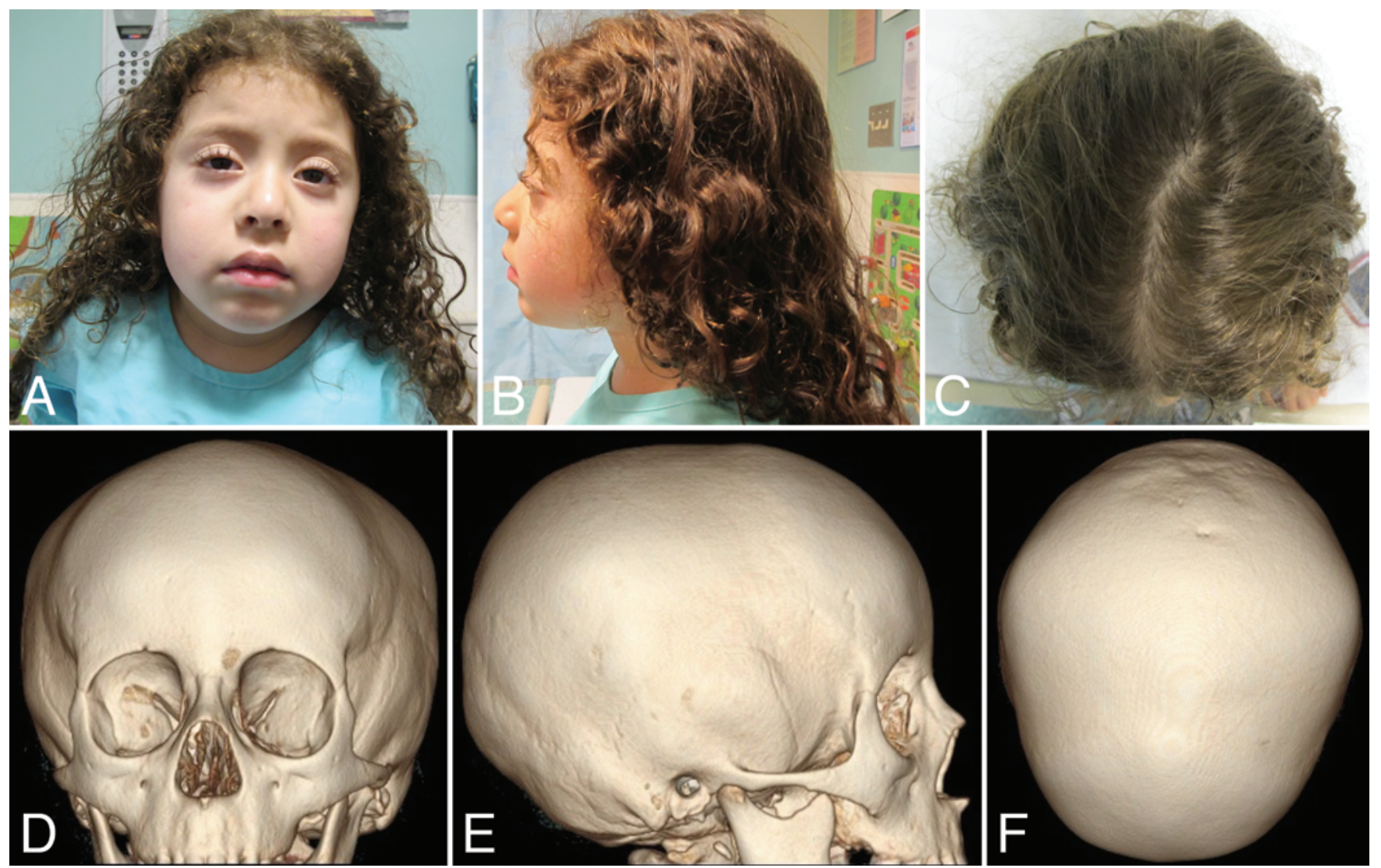

FIG. 2. Patient 14 and CT images (no known syndromic diagnosis). Figure is available in color online only.

tained for all patients revealed a significant decline in percentile head size (Fig. 6) that started at a mean age of 38.6 months (range 8-90 months). This was defined as the first measurement in a sustained trend of declining percentile head circumference. It was noted to occur in all patients prior to definitive diagnosis of PPP and was often the primary reason for referral to our center. The chief complaints at the time of initial presentation are described in Table 1. Upon further evaluation, 16 (94.1\%) of 17 patients presented with some abnormal signs and symptoms, the most common being developmental delay
( $\mathrm{n}=8 ; 47.1 \%)$, followed by recurrent headache or irritability $(\mathrm{n}=4 ; 23.5 \%)$. Three patients $(17.6 \%)$ were initially referred for abnormal facial features (i.e., midfacial hypoplasia and proptosis) and normal head shape, without any other concerning signs/symptoms, and 1 patient presented following the identification of papilledema on routine ophthalmological examination.

CT scans for all patients were reviewed by 4 senior surgeons and demonstrated fusion of multiple sutures. Indications for obtaining a CT scan were clinical suspicion of craniosynostosis $(n=11)$, concerns of new-onset hy-
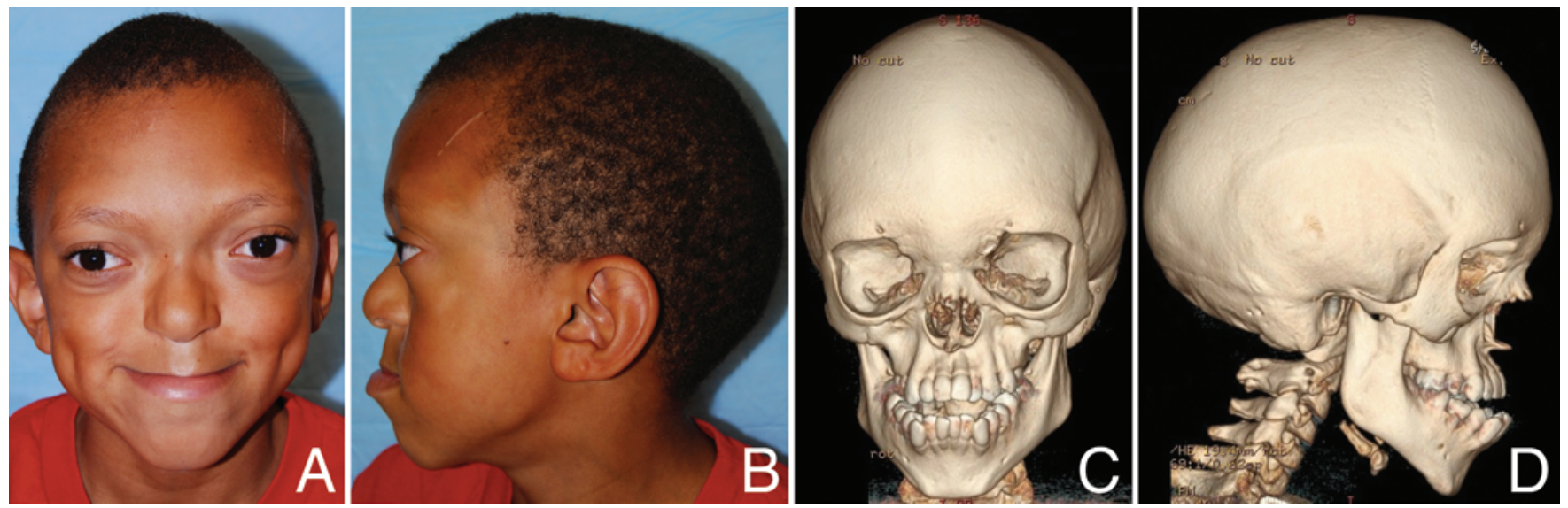

FIG. 3. Patient 15 and CT images (Pfeiffer syndrome). Figure is available in color online only. 


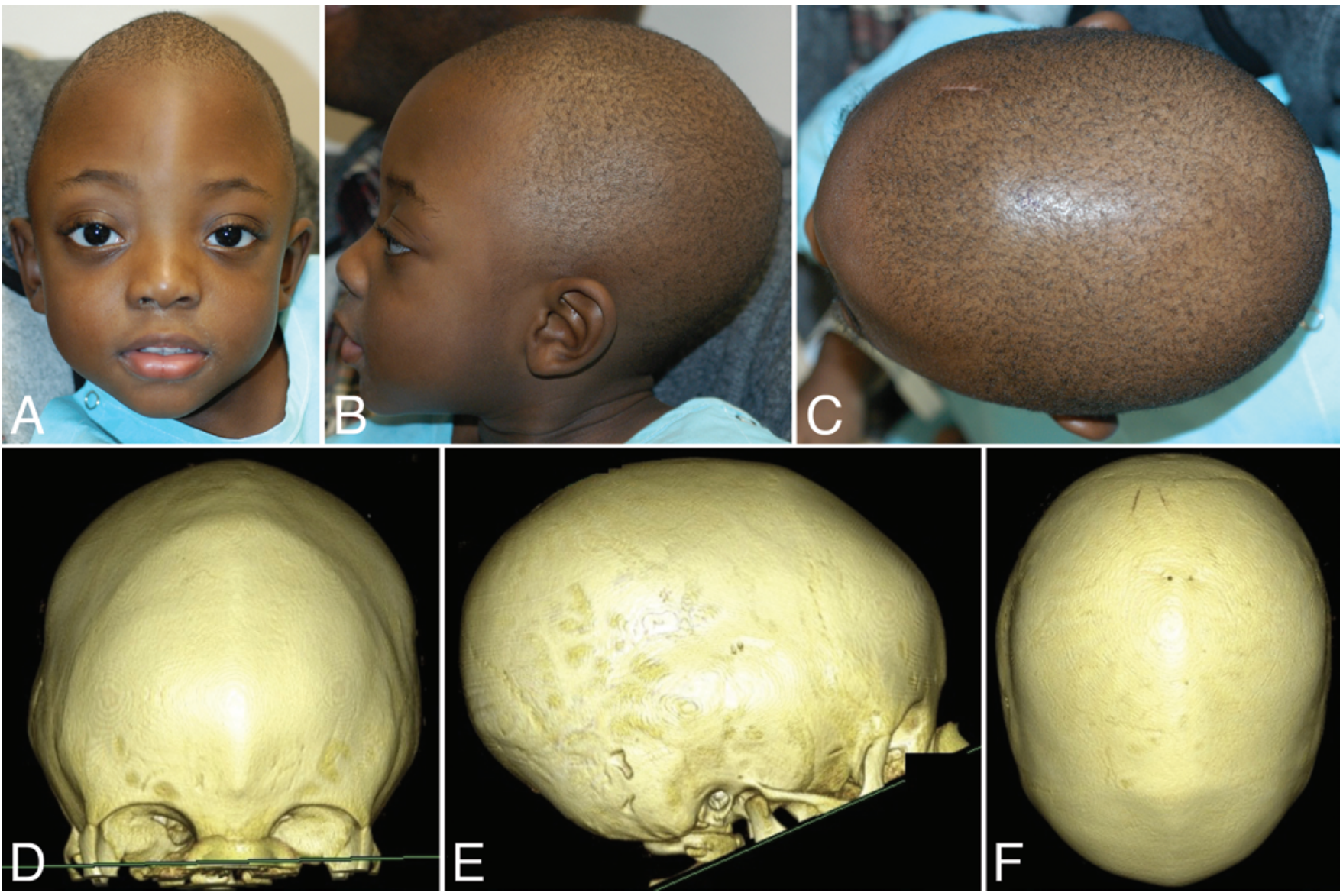

FIG. 4. Patient 10 and CT images (no known syndromic diagnosis). Figure is available in color online only.

drocephalus or follow-up after ventriculoperitoneal (VP) shunt placement $(n=4)$, and declining hearing in a patient with Apert syndrome. One patient with a known Chiari malformation underwent imaging because of a recent history of recurrent falls. Thirteen radiology reports $(76.4 \%)$ documented potential signs of increased ICP, most commonly citing "copper-beaten appearance" or endocortical thinning. Nevertheless, these findings were evident in all studies on retrospective review of the scans. Two CT scans lacked any comment on either sutural patency or endo- cortical appearance despite the presence of fused sutures, endocortical erosion, and loss of cisternal space. Multisuture synostosis was accurately reported by the radiologist for only 9 patients (52.9\%), while for 8 patients (47.1\%) the diagnosis was either missed or incomplete.

MRI was performed preoperatively in 11 patients (64.7\%), typically to assess for hydrocephalus and/or newonset symptoms in the setting of a known Chiari malformation. Of those patients, 3 were noted to have both cerebellar tonsillar herniation (i.e., Chiari Type I malfor-
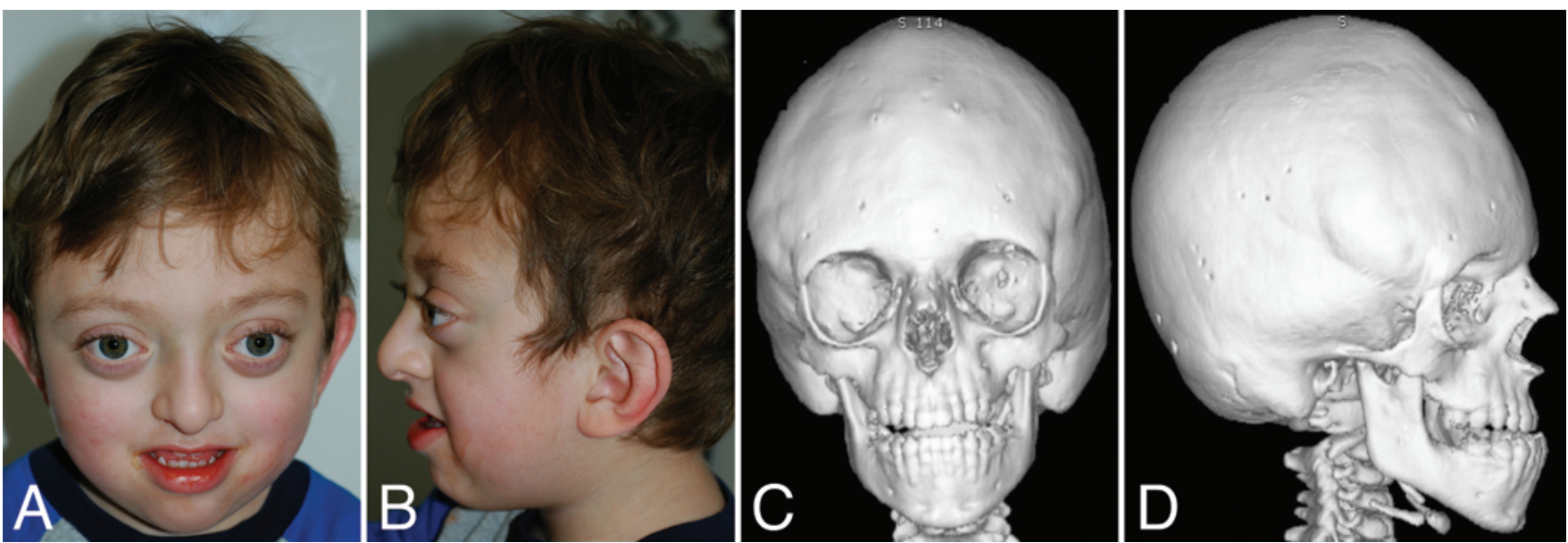

FIG. 5. Patient 6 and CT images (Crouzon syndrome). Figure is available in color online only. 


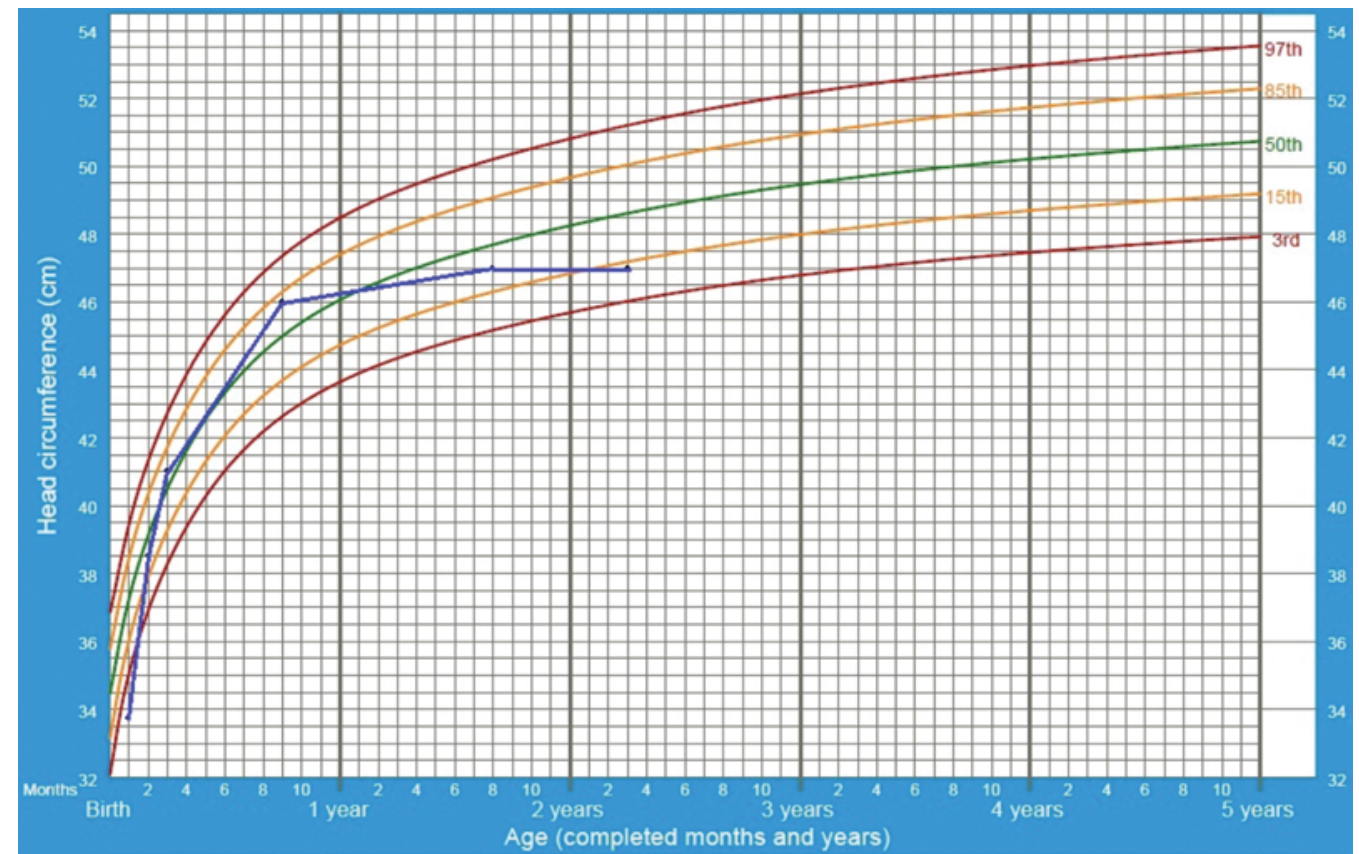

FIG. 6. Representative head-circumference growth chart (of Patient 2) demonstrates precipitous decline in percentile head size prior to formal diagnosis (blue line). Figure is available in color online only.

mation) of varying degrees and cervical syrinx, 3 had a Chiari Type I malformation, 2 patients had ventriculomegaly, 1 had mild tonsillar ectopia, 1 had narrowing of the lateral transverse sinuses, and 1 patient had stenosis of the foramen magnum.

There were 8 patients with objective evidence of elevated ICP. Two patients had papilledema and did not undergo invasive ICP monitoring. Six patients had some form of direct pressure monitoring (4 preoperative ventricular monitoring, 1 lumbar puncture, 1 direct ventricular measurement during shunt placement), and all demonstrated elevated ICP (above $10 \mathrm{~mm} \mathrm{Hg}$ ): 4 had measurements between 25 and $45 \mathrm{~mm} \mathrm{Hg}$, and 2 had more modest elevations $(15-18 \mathrm{~mm} \mathrm{Hg}$ and $15-22 \mathrm{~mm} \mathrm{Hg})$. Of the 6 patients who underwent direct ICP monitoring, only half $(n=3)$ had papilledema.

Definitive bilateral frontoorbital advancement (FOA) with or without lateral and posterior calvarial vault remodeling (CVR) was performed in 10 patients (58.8\%). Six were from the group of 8 aforementioned patients who had objective evidence of elevated ICP; the remaining 4 patients had a persistent decrease in percentile head circumference and CT findings consistent with elevated ICP, including endocortical scalloping and loss of cisternal spaces. Two of the patients underwent cranial expansion for persistently elevated ICP despite previous VP shunt placement (Fig. 7), and 1 of these developed recurrent papilledema following FOA and required another CVR. The remaining patients have remained asymptomatic. Of the 2 patients with a Chiari malformation who underwent CVR but no posterior fossa decompression, both were noted to have persistent but improved appearance of the Chiari malformation postoperatively.

Of the 7 patients who did not undergo FOA, 2 patients were in the group that demonstrated objective evidence of elevated ICP. One patient with mild elevations (ICP $15-18 \mathrm{~mm} \mathrm{Hg}$ ) was successfully managed with Chiari decompression. The other patient (with ICP $25-30 \mathrm{~mm} \mathrm{Hg}$ and papilledema) underwent VP shunt placement and has complaints of intermittent headaches, but has refused definitive operative intervention. Of the remaining patients, 2 underwent VP shunt placement, and 1 of these underwent a subsequent Chiari decompression. Three patients have declined cranial vault expansion or intraventricular pressure monitoring. This group is being followed with observation, serial eye examinations, and imaging as determined by clinical examination. None of these 3 patients have developed papilledema upon serial ophthalmological assessment. One patient reported intermittent headaches while the other 2 patients denied experiencing any symptoms characteristic of elevated ICP. While the absence of papilledema and/or symptoms is reassuring, it is quite possible that these patients have chronic elevations in ICP.
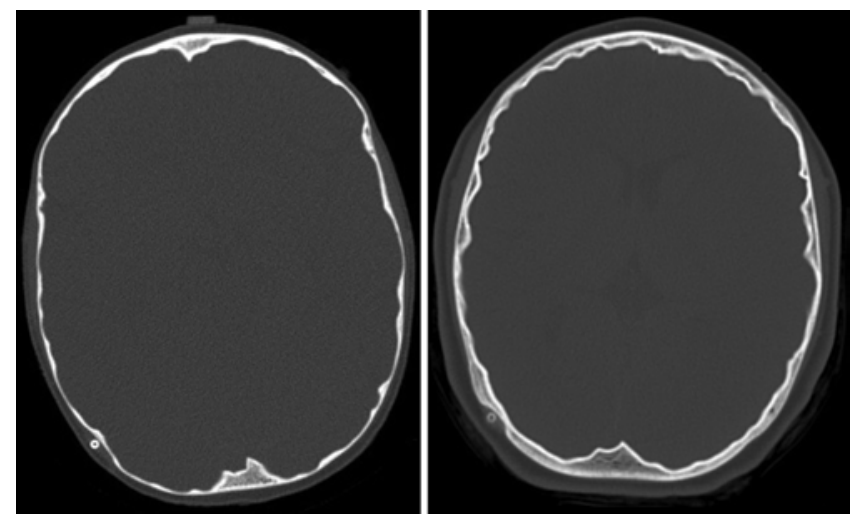

FIG. 7. Axial CT images of Patients 3 (left) and 8 (right) showing characteristic endocortical erosions. 


\section{Discussion}

This retrospective investigation highlights several crucial observations regarding PPP. One of the most important aspects of this condition to recognize is that the effects of postnatal sutural fusion on cranial shape and growth are remarkably subtle and often difficult to detect. The lack of significant cranial dysmorphology in patients with PPP leads invariably to a delay in diagnosis. The age of definitive diagnosis in our patients was 5.2 years, comparable to other reports. ${ }^{2,7,10,11}$ Connolly and coworkers described 15 patients with normal head shapes at birth who went on to develop pansynostosis. ${ }^{2}$ All of these patients had a syndromic diagnosis, the most common of which was Crouzon syndrome, and the mean age at presentation was 5.8 years: this is 4 years older than what has been reported for infants (1.1 years) with other forms of craniosynostosis. ${ }^{2}$ Rogers and colleagues reported a series of 19 patients with PPP who presented at an average age of 32.4 months. ${ }^{11}$ All had a normal or near-normal cranial shape. Reddy and colleagues reported on 11 patients with delayed holocalvarial craniosynostosis, 7 of whom had documented progression of the fusion with time. ${ }^{10}$ The majority of patients had a normal head shape and signs of increased ICP. ${ }^{10}$ Similarly, Foo and coworkers reported 4 patients with what they termed "normocephalic pansynostosis," with an average age at presentation of 3.5 years. ${ }^{4}$ In the absence of aberrant cranial shape, early detection of PPP often hinges on other factors. The most important physical finding is a subtle decline in percentile head circumference. This was observed in all of our patients and is a common finding in other reports. ${ }^{2,11}$ We observed a consistent pattern in our patients' steadily declining percentile head circumference: normal growth immediately after birth, followed by a clearly identifiable, persistent, and gradual decline usually in the later part of the first year. This abrupt change in head growth has only 2 possible explanations: either the latent closure of the cranial sutures is restricting postnatal cranial cerebral growth (i.e., sutures still contribute), or brain growth in these children subsided for some reason, and the fusions occurred secondarily.

Although some authorities argue that the cranial sutures have little or no role in cranial growth after birth and their primary function is in the perinatal period "to allow the child to come through the birth canal," ${ }^{\prime \prime}$ the findings in this patient population suggest otherwise. First, it would be highly unusual for an otherwise normally growing cerebrum to suddenly decelerate in expansion in the absence of some catastrophic insult; no such occurrence could be documented in our patients. Moreover, nearly every patient had clinical findings suggestive of intracranial hypertension, such as severe endocortical erosion $(n=13)$ or papilledema $(n=5)$, symptoms that imply undergrowth of the cranium and not the brain. As in other reports, $2,7,10$ the most ubiquitous finding of elevated ICP was severe endocortical bone erosion noted on CT. Some authors have questioned whether this "copper-beaten" pattern is sensitive for ICP elevation, $1,12,14,15$ although the intraoperative appearance of the brain and endocranium in each case leaves us with little doubt that these patients had elevated ICP.

Six of the 11 patients in our study who underwent MRI had a Chiari malformation. This finding was not un- expected as the anomaly is known to occur at a significantly higher frequency among patients with syndromic forms of craniosynostosis. ${ }^{13}$ Nevertheless, craniocerebral disproportion in patients with craniosynostosis has been described as a potential mechanism for the occurrence of Chiari malformation in these patients, ${ }^{5}$ and there is some debate regarding the optimal management of this subset of patients. There are several reports of resolution of craniosynostosis-associated Chiari malformation following cranial vault expansion, which obviated the need for decompression. $3,9,13$

Hydrocephalus can also be noted in this patient population and may induce Chiari malformation. ${ }^{13}$ Four of our patients underwent VP shunt placement, 1 of whom subsequently underwent posterior fossa decompression. Of the remaining 3 patients, 2 underwent CVR/FOA, and 1 had posterior fossa decompression alone. Our limited patient numbers prevent us from forming any conclusion as to the benefit of one approach versus the other to address the finding of Chiari malformation in the PPP population. One patient with Pfeiffer syndrome developed papilledema after undergoing FOA at 9 weeks of age and required a repeat CVR at 7 years of age. Although the cause of inadequate cranial growth after the initial release procedure is not discernable, possibilities include the very young age at which the procedure was done and the deleterious effect of fibroblast growth factor receptor mutation on bony growth.

In addition to the changes in cranial growth, a majority of our patients with PPP had a syndromic diagnosis, the most common being Crouzon syndrome. Eighty-seven percent (13 of 15) of patients with PPP described by Connolly and coworkers had Crouzon syndrome, and all patients had midfacial retrusion but normal head shapes. ${ }^{2}$ Hoefkens and coworkers documented PPP in 9 of 73 patients with Crouzon syndrome. ${ }^{7}$ Affected patients had absent or mild clinical features, such as exorbitism and midfacial retrusion, in early infancy that appeared to progress with the onset of craniosynostosis. The authors referred to these patients as a "postnatally expressed subtype" of Crouzon, a finding reportedly discussed by Dr. Tessier. ${ }^{8}$ The large series by Rogers and coworkers ${ }^{11}$ reported more syndromic variation, including patients with SaethreChotzen and Pfeiffer as well as several patients with no clearly identifiable syndromic diagnosis. One common finding in these reports is a normal cranial shape that often failed to raise timely suspicion of craniosynostosis.

\section{Conclusions}

Based on our findings, and those reported in other studies, it is our contention that any infant or child with a known craniosynostosis syndrome and a normal or nearnormal cranial shape should undergo CT evaluation to rule out PPP. Nevertheless, some syndromic infants with PPP may have a very mild phenotype when the process of pan fusion occurs. ${ }^{11}$ Consequently, CT evaluation is recommended for any child with a steadily and persistent declining percentile head circumference.

\section{References}

1. Agrawal D, Steinbok P, Cochrane DD: Significance of beaten copper appearance on skull radiographs in children with 
isolated sagittal synostosis. Childs Nerv Syst 23:1467-1470, 2007

2. Connolly JP, Gruss J, Seto ML, Whelan MF, Ellenbogen R, Weiss A, et al: Progressive postnatal craniosynostosis and increased intracranial pressure. Plast Reconstr Surg 113:1313-1323, 2004

3. Di Rocco C, Velardi F: Acquired Chiari type I malformation managed by supratentorial cranial enlargement. Childs Nerv Syst 19:800-807, 2003

4. Foo R, Whitaker LA, Bartlett SP: Normocephalic pancraniosynostosis resulting in late presentation of elevated intracranial pressures. Plast Reconstr Surg 125:1493-1502, 2010

5. Gault DT, Renier D, Marchac D, Jones BM: Intracranial pressure and intracranial volume in children with craniosynostosis. Plast Reconstr Surg 90:377-381, 1992

6. Goodrich JT: Editorial: Cranial orthosis therapy. J Neurosurg Pediatr 12:203-205, 2013

7. Hoefkens MF, Vermeij-Keers C, Vaandrager JM: Crouzon syndrome: phenotypic signs and symptoms of the postnatally expressed subtype. J Craniofac Surg 15:233-242, 2004

8. Kreiborg S: Postnatal growth and development of the craniofacial complex in premature craniosynostosis, in Cohen MM, MacLean RE (ed): Craniosynostosis: Diagnosis, Evaluation, and Management. New York: Oxford University Press, 2000, pp 158-174

9. Levitt MR, Niazi TN, Hopper RA, Ellenbogen RG, Ojemann JG: Resolution of syndromic craniosynostosis-associated Chiari malformation Type I without suboccipital decompression after posterior cranial vault release. J Neurosurg Pediatr 9:111-115, 2012

10. Reddy K, Hoffman H, Armstrong D: Delayed and progressive multiple suture craniosynostosis. Neurosurgery 26:442-448, 1990

11. Rogers GF, Greene AK, Proctor MR, Mulliken JB, Goobie SM, Stoler JM: Progressive postnatal pansynostosis. Cleft Palate Craniofac J [epub ahead of print], 2014
12. Rühli FJ, Nicklisch N, Alt KW: A historical case of beatencopper cranium. J Neurosurg 106 (1 Suppl):71-73, 2007

13. Strahle J, Muraszko KM, Buchman SR, Kapurch J, Garton HJ, Maher CO: Chiari malformation associated with craniosynostosis. Neurosurg Focus 31(3):E2, 2011

14. Tuite GF, Evanson J, Chong WK, Thompson DN, Harkness WF, Jones BM, et al: The beaten copper cranium: a correlation between intracranial pressure, cranial radiographs, and computed tomographic scans in children with craniosynostosis. Neurosurgery 39:691-699, 1996

15. van der Meulen J, van der Vlugt J, Okkerse J, Hofman B: Early beaten-copper pattern: its long-term effect on intelligence quotients in 95 children with craniosynostosis. J Neurosurg Pediatr 1:25-30, 2008

16. Virchow R: Ueber den Cretinismus, namentlich in Franken, und über pathologische Schädelformen. Verh Phys Med Gesellsch Würzburg 2:231-271, 1851

\section{Author Contributions}

Conception and design: Rogers, Oh, Keating. Acquisition of data: Rogers, Wood, Oh. Analysis and interpretation of data: Rogers, Wood, Oh. Drafting the article: Rogers, Wood, Oh. Critically revising the article: all authors. Reviewed submitted version of manuscript: all authors. Approved the final version of the manuscript on behalf of all authors: Rogers. Administrative/technical/ material support: Wood, Magge. Study supervision: Rogers, Oh, Keating, Boyajian, Myseros.

\section{Correspondence}

Gary F. Rogers, Department of Plastic Surgery, Children's National Medical Center, 111 Michigan Ave., NW, Washington, DC 20010. email: grogers@cnmc.org. 